\title{
CETA, an Innovative Agreement with Many Unsettled Trajectories
}

\author{
Michèle Rioux, Christian Deblock, Guy-Philippe Wells \\ Center for Research on Integration and Globalisation, Université du Québec à Montréal, Montréal, Canada \\ Email: rioux.michele@uqam.ca, deblock.christian@uqam.ca,wells.guy-philippe@uqam.ca
}

How to cite this paper: Rioux, M., Deblock, C., \& Wells, G.-P. (2020). CETA, an Innovative Agreement with Many Unsettled Trajectories. Open Journal of Political Science, 10, 50-60. https://doi.org/10.4236/ojps.2020.101005

Received: June 21, 2019

Accepted: December 28, 2019

Published: December 31, 2019

Copyright (c) 2020 by author(s) and Scientific Research Publishing Inc. This work is licensed under the Creative Commons Attribution International License (CC BY 4.0).

http://creativecommons.org/licenses/by/4.0/

(c) (i) Open Access

\begin{abstract}
Can trade agreements integrate innovations and progressive dispositions? In this era of fast changes linked to globalization and technological changes which fuel discontent, this question has emerged in the literature and in the negotiation processes of many recent agreements. In the first section of this article, we will introduce the structural changes that are beneath the surface of recent trade agreements using a typology of trade agreements enabling comparative analysis. In the second section, we will discuss some of the most important innovations of the Comprehensive Economic and Trade Agreement (CETA) negotiated by Canada and the European Union. In the third section, we will see that part of the innovative nature of CETA, its evolutionary nature, brings many unsettled trajectories. In the fourth section, we will discuss how CETA is further unsettled in its trajectory because it puts into relation two distinctive integration models highlighted in our typology, one developed in Europe and the other in North America and, furthermore, because of the more general context that also puts into play Asia and China as emerging shapers of economic trade agreements.
\end{abstract}

\section{Keywords}

Trade, Agreements, Innovation, Transatlantic, Integration, Regulation, Cooperation, Globalization, Innovation, Progressive Trade

\section{Introduction}

The Comprehensive Economic and Trade Agreement (CETA) negotiated by Canada and the European Union (EU) is nowadays one of the most innovative trade agreements. It falls into what we call a third generation of trade agreements (Rioux, Deblock, \& Viau, 2015). A first generation of trade agreements was modelled on the European integration process using a community building 
approach while a second generation was shaped by the North American Free Trade Agreement which is based on a contractual approach. The third wave of trade agreement is clearly pointing to a new generation of agreements with distinctive aspects from the two first generations. CETA is a good illustration of the innovations of this new model emerging.

CETA does innovate in many ways. Innovations include the definition of investment and the investor-state dispute settlement mechanism, the recognition of professional qualifications, the defense of culture and services as well as many other new path breaking articles and chapters affecting trade and investment across the Atlantic.

Yet, the real innovation is not in those areas per se, but in the fact that it introduces international regulatory cooperation into the body of the text and put in place institutional mechanisms combining dialogue and trade obligations with regards to regulations and governance issues. It does so by introducing a chapter on regulatory cooperation as well as the institutionalization of regulatory forums, including a civil society forum involved in the implementation process of chapters dealing with sustainable development, labor and the environment (Deblock \& Wells, 2017).

In the first section of this article, we will introduce the structural changes that are beneath the surface of recent trade agreements. In the second section, we will discuss the innovations of CETA. In the third section, we will focus on the progressive elements of the agreement. The fourth section will question its impacts as its future trajectories are very unsettled. CETA is unsettled mainly, we argue, because it puts into relation two distinctive integration models, one developed in Europe and the other in North America and because of the more general context that also puts into play Asia and China as strong shapers of the future of economic and trade agreements (Deblock \& Lebullenger, 2018).

\section{Structural Changes and the Nature of Trade Agreements}

Generated by the technologies produced and the rules written in the 20th century, global interconnections induce a renewal of economic and trade regulation. Trade is fundamentally changing. Transnational economic structures and networks deployed by multinational-even global-companies that cross territorialized political systems do not fail to overthrow the relations of authority between large economic units and political entities. This increases the rivalry between national or regional spaces that seek to pull themselves together, while losing important levers of economic regulation. The risks of competition between regions of the world are then exacerbated by the fractures resulting from competition between economic systems and political systems. We are witnessing the deepening of globalization through the interaction of economic, legal, social and political spaces, in order to make them interoperable. And in a multipolar world where the United States no longer stands out unchallenged with Asia gaining in influence, private powers such as Google, Amazon, Apple or Facebook remind 
us of a certain Rockefeller empire of the early twentieth century that can only amplify the uncertainties and risks of global disorder.

We had identified second generation agreements with NAFTA that led away from the EU integration model. When NAFTA came into effect more than two decades ago, the revolution in information and communications technology was still in its infancy, the web had just emerged and, therefore, e-commerce did not exist. The emergence of global value chains (GVCs) is a second factor. Until the 1990 s, the internationalization of multinational firms basically meant the establishment of subsidiaries abroad and designed primarily to protect multinationals, NAFTA-type agreements were part of a dynamic of this kind of internationalization of firms. The internationalization has changed with the emergence of global value chains linking independent yet networked producers, distributors, large and small across the world. One word summarizes this new economic reality: fluidity-that of cross-border flows along GVCs and throughout networks. Furthermore, we have entered a new world of interconnection that is not looking for fusion or unity but rather simply to connect different systems and units through codes, networks, data, standards.

The first generation of agreements had the ideal model of the European model aimed at nothing less than multidimensional regional integration (trade, security, money, law and politics). Integration is a strong concept, combining ideas of fusion, concentration and, ultimately, unity that makes less sense today as the economy grows more networked (Ares, Boulanger, \& Deblock, 2016). Recent trade agreements are very ambitious but there are by no means, aiming at creating a single unit like the EU. New words, like comprehensive and partnership, combine to define what Deblock (Deblock, 2016) depicted as an "interconnection" model that is essentially geared towards "regulatory cooperation and governance". This issue is now at the core of discussions within the OECD, APEC or new trade agreements, according to terms and principles very different from previous negotiations.

We now have before us a third generation of trade agreements that go beyond trade issues in the strict sense and that tend to have a new "progressive" orientation. We have entered a New World, that of interconnection, and it is in this context that the model of third-generation agreements, which stand out singularly from the first and second generations of trade agreements, makes perfect sense.

With the new networks, gateways are created to smoothly circulate information between systems that function independently and necessarily share the same codes or language as it would be the case with a unified system (De Bardeleben \& Leblond, 2011). Networks can be cross-border, like the value chains that cross regions, continents, the world, but they are now mostly outside the borders, and increasingly dematerialized like the Internet, to which E-commerce owes its existence, the new engine of world trade. Harmonization or interoperability of rules becomes a key element here; whether it is to establish recognized, effective technical, macro-prudential, social, environmental, etc. We are at the 
heart of a project which, under the pressure of change, governments have no alternative than to adjust to using multiple ways, including trade agreements, investment agreements and regulatory cooperation (Verdier, 2010).

We are on new grounds that require trade agreements based on new methods of negotiation taking into account issues that are all but strictly commercial. It is the particularity of new agreements like CETA to propose institutional frameworks to advance a "dialogue between regulators", to use an expression used in an interview by Pascal Lamy ${ }^{1}$. CETA is one of them, along with the mega-partnerships of the Trans-Pacific Partnership which is now the CPTPP (Comprehensive and Progressive Agreement for Trans-Pacific), the Atlantic Partnership, and the Regional Comprehensive Economic Partnership (RCEP) or the United States, Mexico, Canada Agreement (USMCA).

But let's concentrate on CETA. CETA is opening new institutional trajectories for the regulation of transatlantic trade and investment. We see emerging transnational regulatory responses accelerating the disappearance of the boundary between the public and private spheres at various levels-local, national, international and global-giving way to a complex system of networks between authorities endowed with overlapping rights and obligations. This participates in the deepening and widening a regulatory cooperation.

\section{Transatlantic Regulatory Cooperation}

In this new context, States move forward and, short of being able to establish global shared rules and codes, they seek mutually recognized or interoperable technical, macro-prudential, social, environmental norms, etc. They do this using different instruments, and trade agreements can certainly contribute. Most often, this process is increasing privately led or induced but such institutional trajectories ultimately find their way back to national systems, and sometimes through trade agreements. Trade agreements always have the effect, once ratified, of modifying the laws, regulations and other administrative procedures of the contracting Parties. Initially limited to goods and tariffs, trade disciplines were extended to non-tariff barriers and then to services to cover trade facilitation today.

CETA has indeed been now implemented for almost two full years and it is clear that it created a new framework for dialogue in the trade and economic relations between Canada and the EU ${ }^{2}$. First, CETA points to international regulatory cooperation as a main ongoing trajectory in terms of market access, equal treatment and dispute resolution but also with regards to new subjects like labor, ${ }^{1}$ Richard Hiault, "Pascal Lamy: 'Le Traité transatlantique est un accord de troisième génération"”, LesÉchos (20 octobre 2015), Les Echos $<$ www.lesechos.fr/20/10/2015/lesechos.fr/021418267703_pascal-lamy-----le-traite-transatlantique-e st-un-accord-de-troisieme-generation--.htm $>$.

${ }^{2}$ For an analysis of relations between the European Union and Canada and the content of the agreement, see Christian Deblock, Joël Lebullenger and Stéphane Paquin, Un nouveau pont sur I Atlantique: L'Accord économique et commercial global, Québec, Presses de l'Université du Québec, 2015. 
the environment, small and medium-sized enterprises and domestic regulations. Second, it introduces a new institutional framework, partnership, with implies new institutions, dialogue and advisory groups that will impact on its interpretation and implementation, and thus on its evolutionary path.

CETA deals with regulatory cooperation in a number of areas, including in chapter 12 dealing with Domestic Regulation, chapter 21 addressing Regulatory Cooperation, chapter 25 in relation to Bilateral Dialogues and Cooperation, and chapter 26 setting administrative and institutional arrangements (listing and specifying the list and terms of reference of the specialized committees, including the Joint Management Committee for Sanitary and Phytosanitary Measures, the Regulatory Cooperation Forum, the Committee on Geographical Indications, etc.-Article 26.2). Many other chapters involve, in many diverse ways, regulatory cooperation, notably when it comes to electronic commerce, telecommunications, technical barriers to trade, and sanitary and phytosanitary measures.

Let's focus on Chapter 21 of CETA. Four objectives are defined in chapter 21: 1) to contribute to the protection of the life, health or safety of persons or animals, the preservation of plants and the environment; 2) to build trust, deepen mutual understanding and building on each other's expertise, 3) to facilitate bilateral trade and investment and 4) to improve the economic competitiveness and efficiency. The idea is to eliminate barriers to trade and investment, while fostering innovation and effective regulatory processes that support public policy objectives. CETA affirms the sovereignty of the Parties to legislate and regulate, the high level of quality sought for regulation and the freedom to choose to participate in cooperative activities mutually agreed upon. The goal is not so much to seek harmonization as to make the regulations compatible, to favor their convergence and thus to facilitate trade. Reciprocity, like equal treatment, as cornerstones of the modern trading system, does not fit this framework. Regulations, like any institution, are not easy to change or even less to bring closer since differences are rooted in history, politics and values. In many ways, when protectionism is alleged, it relates to the differences between regulatory systems and this most often is the tip of the iceberg of "singular and discriminatory" national regulatory systems. Certainly, it is difficult to make the difference between protectionist or restrictive measures and measures justified by legitimate public policy objective in the public interest.

With CETA, a Regulatory Cooperation Forum (RCF) is created "to facilitate and promote regulatory cooperation" and is co-chaired by high-level representatives at the Deputy Minister level for Canada and Executive Director for the European Commission. It reports to the Joint Committee. In CETA, the path chosen is that of cooperation, dialogue and transparency. The RCF does not have decision-making authority but its recommendations will count and, through the Joint Committee, can become decision if accepted by both Parties.

Pluralism is also a key element (Deblock \& Wells, 2017). The cooperative di- 
alogue is not limited to the regulatory and regulatory agencies alone; it is extended to "private entities". The term covers interested stakeholders, including representatives of the business community, academia, non-governmental organizations and specialized organizations. This opening reflects a new trend in the field of regulatory cooperation as not only are specialized technical organizations, private or not, increasingly involved in setting norms and standards, but there is also growing collaboration between government agencies and members of civil society.

It is questionable, however, whether by giving it a very broad mandate and by involving private entities in its operation, the FRC could not make it possible to deal more effectively with societal issues such as the environment, labor, sustainable development, culture, etc. Although they are the subject of specific chapters or exception in CETA, as in many other trade agreements, their treatment in the agreements is still debated and the results do not satisfy anyone. The RCF could offer the opportunity to broaden the debate on transversal issues and thereby interacting with dialogue and cooperation activities that are the subject of the chapters regarding sustainable development, labor and the environment. This would contribute to have regulatory cooperation build on a more progressive pillar rather than one that is strictly technical/trade oriented. This leads us to consider the Sustainable Development chapter and two chapters it covers, labor and environment.

\section{Progressive Transatlantic Regulatory Trajectory}

We will now concentrate on labor more specifically. The innovation of CETA, in this regard, is that it was the first time a social clause was negotiated in a North-North trade agreement since NAFTA, which really incorporate the social clause because Mexico was involved. Canada and the EU are two entities that have actively promoted the diffusion of such social clauses in trade agreements but CETA is the first social clause between two developed trade partners, between two partners that have insisted on integrating labor chapters in trade agreements and between two transatlantic trade partners. It is important since it will likely confront or build a bridge between two approaches to these chapters-a North American approach versus a European approach. Will CETA lead to a transatlantic model or to a way to make compatible two different approaches? Nobody can tell as institutional trajectories are not paved with certainty.

Chapter 23 of CETA deals with labor issues. The chapter can lead one to conclude that there was a compromise in terms of obligations and a predominance of European preferences in terms of dispute and settlement mechanism. On substance, the EU insisted on ratification of fundamental ILO (International Labor Organization) Conventions and on the integration of the chapter into a wider Sustainable Development Chapter in line with the European social clause model. Yet, the principles and obligations reflects a real consensus on the importance of the ILO Declaration on Fundamental Principles and Rights at Work 
(1998) which commits Member States, even if they have not ratified the relevant Conventions, to respect rights related to freedom of association and the effective recognition of the right to collective bargaining, the elimination of forced or compulsory labor, the abolition of child labor and the elimination of discrimination in respect of employment and occupation. In CETA, thanks in part to the pressure of the EU, Conventions have to be ratified, and Canada has now ratified all 8 relevant Conventions.

The chapter covers the main provisions dear to both parties. On the Canadian side, a non-derogation clause was important, the emphasis on public participation in the process and finally, an institutional mechanism on two levels, with a Sustainable Development Council that replaces the Ministerial Council found in previous Canadian agreements, and a second level, the establishment of focal points in the ministries.

On the issue of enforcement, CETA fell short of a chapter tied to the dispute settlement mechanism with penalties or sanctions. The enforcement mechanism is based on a conciliation procedure and, if necessary, the constitution of a panel of three experts. This falls short of Canada's insistence on a strong enforcement approach based on the same dispute settlement mechanism that applies to other chapters of the agreement. Let's recall the debate that almost derailed the negotiation on the investor-State dispute settlement resolution leading to a new institutional design unique to CETA (Magnette, 2017).

In contrast, no procedure provides for any penalty for the labor chapter, contrary to provisions related to other trade and investment chapters. There are two approaches in integrating social clauses in trade agreements: 1) conditional; and, 2) promotional. The conditional approach is more used in the North American model which makes the enforcement of labor chapters subject to penalties, or to dispute settlement mechanisms with relatively strong sanctions. The promotional approach, adopted by the EU, considers cooperation is more effective than sanctions or penalties.

Yet, the main innovation is the Civil Society Forum which will be very important in the future trajectories of CETA. CETA is potentially an evolutionary agreement and this is very innovative. The civil society forum was created with the aim of increasing the involvement of organizations in the implementation of the agreement. The forum also aims to enable civil society to bring its concerns to the attention of governments. In order to make this mechanism work, the Government of Canada has established a national advisory group of labor and environmental organizations, such advisory group existed in Europe with prior agreements.

While these initiatives are still recent, the capacity of these mechanisms to effectively relay the demands of civil society organizations needs to be assessed. Two models are interacting in this regulatory framework and there are many institutional uncertainties regarding the different interpretation of the text and how it translates in concrete terms both sides of the Atlantic. 


\section{Unsettled Trajectories}

If CETA is innovative and perhaps evolutionary, its future is uncertain. Highly sensitive national regulations are now often presented as the last major obstacles to the free movement of goods and services, capital and even people. Yet, those regulations are at the core of our national systems and reflect societal values and priorities that should not be equated to protectionist measures even though in some instances they might indeed have impacts on trade and investment. It is controversial to distinguish between what is legitimate and what belongs to the order of the common good and public interest and diverse forms of disguised protectionism. But the essential is not in this issue. Globalization and paradigm shifting information and communication technologies have profoundly disrupted production methods, consumption patterns, and lifestyles. Interconnection, the networking of global value chains, the dematerialization of trade, and its deterritorialization, are at the heart of an upheaval that fundamentally change trade flows and relations, but also the vision we have of trade and how it should be governed. In this fast changing world economy, regulations are not changing fast enough and cooperation is very complex (Breault \& Rioux, 2019).

It is no longer enough for markets to be open across boundaries and to allow for fair competition within borders. More important is that national regulatory systems need to be interoperable and ensure the fluidity in a new trade system that has arisen with new technologies bringing national economic systems closer to one another, most often colliding or conflicting, a situation that is not good for anyone, except for those speculating on those differences. This era is undoubtedly marked by the seal of interconnected and interoperable regulatory systems. The OECD has embarked on this challenge, like other international organizations and, since the turn of the current decade, trade agreements have also made strong incursion into this domain of international cooperation. CETA is part of this transformation. Regulatory cooperation is the subject of particular chapters, but it is also cross-cutting. Yet, the digital transatlantic market has many significant regulatory controversies (taxation, fiscal issues, ...) which lead us to caution and to conclude on the very uncertain future of CETA in terms of real and effective innovations and progressive regulations.

The way ongoing cooperation and enforcement mechanisms are going to work is still unclear. CETA is an evolving agreement. The text of the agreement explicitly provides for this. Who will decide, however, on future developments of the agreement? The text gives latitude providing for civil society and private entities to play an important role. What remains to be seen is who will engage and what trajectory will CETA take. The text of CETA exists, but many chapters still need to be written.

Furthermore, CETA puts into relation two distinctive integration models, one developed in Europe and the other in North America in a context that also puts into play Asia and China emerging in the shapers of economic trade agreements. CETA's future will depend on the articulation of two models of integration, east 
and west of the Atlantic. North America emerged in the 90s as a strong and influential regional model of integration. Stephen Clarkson (2002) has analyzed the nature of trade agreements in North America and talked about them as "constitution" shaping societies, economics and politics. In Apples and oranges: prospects for the comparative analysis of the EU and NAFTA as continental systems, he develops the idea that NAFTA is a constitution and an American mode of regulation ${ }^{3}$. In North America, regional integration has developed as a mainly contractual and essentially strategic model, oriented on economic issues. Partners work to eliminate restrictive policies and regulations rather than to build a common and supranational approach in a multidimensional perspective; i.e. taking into account the public good in economic governance as part of wider social and political integration project. Nowadays, the European Union is an economic, legal, monetary and political reality, even though an imperfect and contested one ${ }^{4}$.

When Canada and the EU enforce an agreement so ambitious like CETA, how does this agreement compare to the regional integration processes underway both sides of the Atlantic, what does it mean for their respective lives and for their interactions that will be increasing in the next years as the agreement become a living experiment and take a life of its own. And, how would CETA interact with a Transatlantic Partnership (TTIP). Negotiations between Europe and the United States that are still planned but controversial would also involve far reaching regulatory cooperation. The EU negotiator for the TTIP made no secret of it. Important issues are the investor-state dispute mechanism, electronic commerce, norms and standards, including labour standards and rights.

Another source of uncertainty is coming from Asia. The TPP (Trans-Pacific Partnership), which became the CPTPP (Comprehensive and Progressive Agreement for Trans-Pacific Partnership), also placed emphasis on regulatory co-operation across the Pacific. Indeed, a very important factor and structural element shaping governance and regulation of economic integration in North America is the importance of Asia and more specifically of China for the region ${ }^{5}$. On this front, North America is being, to a degree, shaped by new views of trade rules and being challenged by China as the leader of the trading system. Since the 1930s, the United States, although with important debates internally, promoted trade liberalization based on a system of legal rules and principles "organizing" the trading system and their relations with trading partners. The actual ${ }^{3}$ Clarkson, Stephen (2000), Apples and Oranges: Prospects for the Comparative Analysis of the EU and NAFTA as Continental Systems, European University Institute, RSC Working Paper 2000/23, p. 3 .

(http://homes.chass.utoronto.ca/ clarkson/publications/Apples\%20and\%200ranges\%20-\%20Prosp ects\%20for\%20the\%20Comparative \%20Analysis\%20of\%20the\%20EU\%20and\%20NAFTA\%20as\%2 oContinental\%20Systems.pdf)

${ }^{4}$ Fiscal and social policies, the effects of the 2008 economic crisis and the management-or lack of-the migration issues in the recent past have paved the way to new risks of implosion of the union (Brexit, most notably).

${ }^{5}$ The Trans-Pacific Partnership, is to transform NAFTA as the three NAFTA countries are involved in the negotiations. 
conflicts that points to a potential trade war means that the United States still want to make the rules of the game and have others comply to gain access to the US market. How does this impact of the future of CETA and its enforcement? This certainly adds to the very unsettled future of CETA that otherwise could secure an innovative course as a promising trade agreement.

\section{Conclusion}

Globalization has led to weaker national and international regulatory frameworks and to the emergence of new "globalist" institutional and normative frameworks. These are contested and this leads to a conflicting landscape that some call deglobalization or slowbalization (Breault \& Rioux, 2019; van Bergeijk, 2019). The rise of populism and discontent about economic inequalities can be related to weak economic and social international institutions. (Stiglitz, 2019). Trade agreements are under pressure to deliver balanced and effective regulation. CETA is a trade agreement that has the potential to be innovative and progressive as it deals with many new areas of regulation.

Yet, CETA lacks a clear path and faces enormous challenges as to succeed it must bridge two different traditions of economic integration and a new model that emerges in Asia. These challenges with the growing trade disputes initiated by the United States may well stop CETA from innovation and social progress. But short of succeeding, contestation and conflicts will shape the future of the world economy.

This article established the very innovative yet fragile nature of CETA and an innovative, evolutionary and progressive third generation agreement. It is significantly shaping a re-articulation of relations between the international, national and provincial orders and between the domains of national policies, especially between trade and labor, trade and culture, trade and investment, trade and regulations ... which requires increased cooperation between ministries at the national level and at the level of relations between the provinces and the federal government. CETA also reflects the emergence of plural governance involving a re-articulation of the relationship between the public authorities and civil society actors and the private sector.

The importance of analyzing CETA as a third generation trade and economic agreement must be understood in the context of its distinctive aspects from early agreements as well as from agreements emerging in Asia and in the transpacific space. Most importantly, it must be further analyzed in terms of its evolutionary nature and whether or not it can and will provide for progressive relation of the transatlantic trade and economic relations. If it does so, perhaps, it can and will be copied and become a new model for other agreements.

\section{Conflicts of Interest}

The authors declare no conflicts of interest regarding the publication of this paper. 


\section{References}

Arès, M., Boulanger, É., \& Deblock, C. (2016). Intégration ou interconnexion? Revue Interventions économiques, 55, 1-38. http://interventionseconomiques.revues.org/2895

Breault, Y., \& Rioux, M. (2019). The Globalization/Deglobalization Dialectic: A Fragmented World Order on the Road to Globalization 2.0? In J. L. Black, M. Johns, \& A D. Thériault (Eds.), The New world Disorder: Challenges and Threats in an Uncertain World (Chapter 10, pp. 207-228). London: Lexington Books.

Clarkson, S. (2000). Apples and Oranges: Prospects for the Comparative Analysis of the $E U$ and NAFTA as Continental Systems. European University Institute, RSC Working Paper 2000/23.

Clarkson, S. (2002). Uncle Sam and Us: Globalization, Neoconservatism, and the Canadian State. Toronto: Woodrow Wilson Center Press. https://doi.org/10.3138/9781442689541

De Bardeleben, J., \& Leblond, P. (2011). The Other Transatlantic Relationship: Canada, the EU, and 21st-Century Challenges. International Journal, 66, 1-7. https://doi.org/10.1177/002070201106600101

Deblock, C. (2016). From Regionalism to Cross-Regionalism (pp. 8-9). Great Insights.

Deblock, C., \& Lebullenger, J. (2018). Génération TAFTA: Les nouveaux partenariats de la mondialisation. Rennes: Presses universitaires de Rennes.

Deblock, C., \& Wells, G. P. (2017). Coopération réglementaire et accords de commerce. Etudes Internationales, 48, 319-345. https://doi.org/10.7202/1044623ar

Deblock, C., Paquin, S., \& Lebullenger, J. (2015). Un nouveau pont sur l'Atlantique. L'accord économique et commercial global entre l'Union européenne et le Canada. Québec: Presses de l'Université du Québec. https://doi.org/10.2307/j.ctt1f1hd25

Hiault, R. (2015). Pascal Lamy: Le Traité transatlantique est un accord de troisième generation. Les Échos.

Magnette, P. (2017). CETA-Quand l'Europe déraille. Bruxelles: Luc Pire.

Rioux, M., Ares, M., \& Huang, P. (2015). Beyond NAFTA with Three Countries: The Impact of Global Value Chains on an Outdated Trade Agreement. Open Journal of Political Science, 5, 264-276. https://doi.org/10.4236/ojps.2015.54028

Rioux, M., Deblock, C., \& Viau, L (2015). L'Aléna conjugué au passé, au présent et au futur. Québec: PUQ. https://doi.org/10.2307/j.ctt1f1hd46

Stiglitz, J. (2019). People, Power and Profits, Progressive Capitalism for an Age of Discontent (366 p.). New York: Norton Company.

van Bergeijk, P. A. G. (2019). Deglobalization 2.0, Trade and Openness During the Great Depression and the Great Recession. Northampton, MA: Edward Elgar.

Verdier, T. (2010) The Political Economy of State Capacity and Trade Policy. PSE Mimeo. 